UNITED STATES DEPARTMENT OF THE INTERIOR GEOLOGICAL SURVEY

\title{
COMPOUND TYPE ANALYSIS APPLIED TO GC-MS STUDIES OF SATURATED HYDROCARBON FRACTIONS FROM GEOLOGIC SAMPLES
}

\section{By}

J. David King and Donald E. Anders U.S. Geological Survey, Branch of $0 i 1$ and Gas Box 25046, MS: 977, Denver Federal Center Denver, Colorado 80225

Open-File Report 81-843

1981

This report is preliminary and has not been reviewed for conformity with U.S. Geological Survey editorial standards 
Introduction.$\ldots \ldots \ldots \ldots \ldots \ldots \ldots \ldots \ldots \ldots \ldots \ldots \ldots \ldots \ldots \ldots \ldots \ldots \ldots \ldots \ldots$

Experimental $\ldots \ldots \ldots \ldots \ldots \ldots \ldots \ldots \ldots \ldots \ldots \ldots \ldots \ldots \ldots \ldots \ldots \ldots \ldots \ldots \ldots \ldots \ldots$.

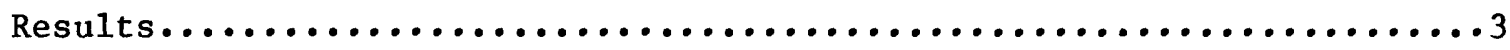

Discussion $\ldots \ldots \ldots \ldots \ldots \ldots \ldots \ldots \ldots \ldots \ldots \ldots \ldots \ldots \ldots \ldots \ldots \ldots \ldots \ldots \ldots$

References.......................................... 
COMPOUND TYPE ANALYSIS APPLIED TO GC-MS STUDIES OF SATURATED

HYDROCARBON FRACTIONS FROM GEOLOGIC SAMPLES

by J. David King and Donald E. Anders

U.S. Geological Survey, Branch of Oil and Gas Resources, Box 25046

MS: 977, Denver Federal Center, Denver, Colorado

\section{INTRODUCTION}

Provided that good separation of individual components is obtained, capillary-column Gas Chromatography-Mass Spectrometry (GC-MS) allows

resolution and identification of complex mixtures. In case of poor

separation, and occasionally when the mixture is extremely complex, a method

of classification of individual compound types is useful.

The method described in this report is capable of producing reconstructed chromatograms of all one- through six-ring napthenes from complex mixtures of saturated hydrocarbon fractions with minimal gas-chromatographic resolution. For example, individual reconstructed chromatograms can be obtained for all cyclohexanes as opposed to decalins or normal alkanes.

Fragment ion intensities have been utilized for nearly thirty years for the quantitative analysis of compound types in petroleum fractions. The first application of this technique was described by Brown (1951). This method is designed to examine a representative spectrum of the entire mixture and mathematically determine the partial pressures (and thus, the percentages) of each compound type present, based on the measured volume and presssure of the inlet system. This involves the summation of the ion intensities of a given ion series $\left(\mathrm{C}_{n} \mathrm{H}_{2 n+z}\right)$ and the subsequent multiplication of this vector with an inverse matrix of "sensitivity coefficients" of all the suspected components in the unknown, thus yielding relative abundances of each compound type. The technique is usually applied to samples introduced to the mass spectrometer via a hot batch inlet system. 
Manual calculation of the relative abundances of the various compound types in a complex mixture is time-consuming and traditionally has been relegated to computers. The availability of mass-spectrometer data systems that can be programmed to manipulate GC-MS data that has been stored on mass media (magnetic disc) now permits vector-matrix manipulations to be easily performed on each scan of a multiple-spectrum GC-MS analysis, yielding relative concentration values for each compound type.

The boiling range of the compounds represented in each individual MS scan is very narrow; generally, only one compound per ion series will be present (isomeric homologs being the exception). Therefore, if the relative concentrations (expressed as a number between 0 and 1) of each compound type in a given spectrum are multiplied by the total ion current of that particular spectrum, ion currents due to individual components are produced. When these ion currents are plotted against retention time (spectrum number), separate reconstructed chromatograms of compound types are obtained. These can be examined quickly for particular compound types, or used to identify peaks in the chromatogram for which individual mass spectra may be of interest. These spectra can then be recalled using the standard data system software.

\section{EXPERIMENTAL}

Alkane fractions extracted from sedimentary rocks were subjected to Standard GC-MS analysis. The instrument used consisted of a Varian mode1-940 gas chromatograph adapted to accept capillary columns, Interfaced to a Kratos MS-30 mass spectrometer via a glass jet searator. The GC column was a 25 meter $\times 0.25 \mathrm{~mm}$ OV-101 WCOT; the flow rate was $1.0 \mathrm{ml} / \mathrm{min}$ of helium; the temperature was programmed from $60^{\circ} \mathrm{C}$ to $275^{\circ} \mathrm{C}$ at $4^{\circ} \mathrm{C} / \mathrm{min}$. The mass spectrometer source operated at $70 \mathrm{eV}$ at a temperature of $250^{\circ} \mathrm{C}$. The mass- 
spectrometer scan rate was 3 seconds per mass decade. Post-data-aquisition processing was accomplished on a DS-50S data system executing user-written FORTRAN programs that actually performed the compound type analysis and plotted the resulting reconstructed chromatograms.

\section{RESULTS}

A sample was collected from the Wilmington oil field, Los Angeles Basin, at a depth of $9,511 \mathrm{ft}(2,899 \mathrm{~m})$. These rocks contain sapropelic organic matter from the Tertiary Period (Mohnian and Luisian Stages). Figure 1 shows a portion of the alkane-fraction chromatogram from this organic matter. Three reconstructed chromatograms of simultaneously eluting alkanes are displayed: 1. the upper trace representing the total ion current (TIC), 2 . the middle trace representing $\mathrm{N}+\mathrm{ISO}$ alkanes, and 3 . the lower trace representing fourring naphthenes. The relative amounts of each compound type in the displayed chromatogram (whether plotted or not) is shown below the chromatograms. The matrix coefficients used for this analysis are those from Lumpkin (1956). The utility of the technique is illustracted by interpretation of the partially resolved doublet in the region of scan number 460 . The first peak seems to be a normal or branched hydrocarbon and the second appears in the four-ring naphthene trace. Examination of the spectra of these two peaks indicates that they are $\mathrm{n}-\mathrm{C}_{29} \mathrm{H}_{60}$ and an isomer of ergostane (a four-ring naphthene). 


\section{DISCUSSION}

Although group-type analysis has been developed as a tool for quantitative analysis of mixtures introduced through a batch inlet, it has been demonstrated here that this technique is also applicable to GC-MS. However, the quantitative accuracy of this application has yet to be demonstrated. Preliminary investigations have indicated that sensitivity coefficients can be determined from spectra of standards obtained from GC peaks if distortions due to change in concentration during the scan and background interferences are dealt with properly.

Coefficients utilized for the analysis of unknowns by GC-MS should be obtained by GC-MS analysis of standard compounds rather than by batch inletMS. Sensitivity coefficients for a given compound type determined by the GCMS method are derived by summing the individual ion intensities representing that compound type and then expressing this sum as a percentage of the total ion current. This is done for known compounds and assumes, on the basis of evidence presented by Hood (1958), that the ion current is proportional to the amount of sample entering the source. Therefore, the sensitivity coefficients for any given series should theoretically be constant throughout the elution of the GC peak. However, if the total ion current is calculated on the basis of all ions produced in the source (including background ions such as $\mathrm{CO}_{2}$, argon, column bleed, air, etc.) calculated sensitivities will be affected as shown in figure 2A. As soon as the background ion intensities become insignificant in comparison to the intensities of the ions from the standard, the sensitivity coefficients will reach a value very close to that obtained by steady state introduction of the standard through a batch inlet. Figure 2B shows the result of excluding background ions from the total ion current calculation. Even though this correction seems to yield better average 
values for sensitivity (S), and even though preliminary results suggest distortion due to concentration change with time is as biased in the high-mass range as it is in the low-mass range, and sensitivity coefficients should be calculated only from scans near the GC peak maximum intensity or from an average of several values of $\mathrm{S}$, taken from well within the peak.

In complex mixtures, accurate calculation of the sensitivity-coefficient matrix is also highly dependent upon the proper selection of ions to represent the various compound types. Ideally, the fragment ions chosen to represent a given compound type would be a unique set of ions offering little or no interference to the ion fragments of other compound types present in the mixture. In practice, selection of fragment ions is less than ideal: $\mathrm{m} / \mathrm{z} 191$ and 205 are prominent ions found in the mass spectra of tricyclic and pentacyclic hydrocarbons of biological origin. Traditionally, these two ions have been assigned primarily to the ion series representing tricyclic compounds; however, in sediments where the pentacyclic compounds are primarily derived from pentacyclic triterpenoids, their contribution is greatest from the pentacyclic napthenes.

Figure 3 shows the discrepancy arising from the use of the $\mathrm{m} / \mathrm{z} 191$ ion in the three-ring naphthene series when pentacyclic triterpanes are present. Conventional interpretation reveals that the identity of the peak at scannumber 524 is in fact a pentacyclic compound $\mathrm{C}_{30} \mathrm{H}_{52}$, probably gammacerane, which does not belong in the three-ring series as indicated by the program. Another consideration is the expansion of this technique to GC highresolution MS using a series of ions such as those suggested by Gallegos and others (1967). Chromatograms of alkanes, aromatics, and even some heterocyclic sulfur compounds could be produced from an unresolved total ion chromatogram. 
From an analytical point of view, the application of the herein described method to geochemical samples is a much more definitive correlation tool than the mere quantitative distribution of the various compound types within a hydrocarbon mixture. This method enables us to look at the changes in the distribution of the homologs within the various compound types as a function of depth of burial (maturation), depositional environment, source material and migration and may prove to be a useful tool in petroleum source-rock studies.

\section{REFERENCES}

Brown, R. A., 1951, Compound types in gasoline by mass spectrometer analysis: Analytical Chemistry, v. 23, p. 430 .

Gallegos, E. J., Green, J. W., Lindeman, L. P., LeTourneau, R. L., and Teeter, R. M., 1967, Petroleum group-type analysis by high resolution mass spectrometry: Analytical Chemistry, v. 39, p. 1833.

Hood, Archie, 1958, Standardization of mass spectra by means of total ion intensity: Analytical Chemistry, v. 30, p. 1218.

Lumpkin, H. E., 1956, Determination of saturated hydrocarbons in heavy petroleum fractions by mass spectrometry: Analytical Chemistry, v. 28, p. 1946 . 


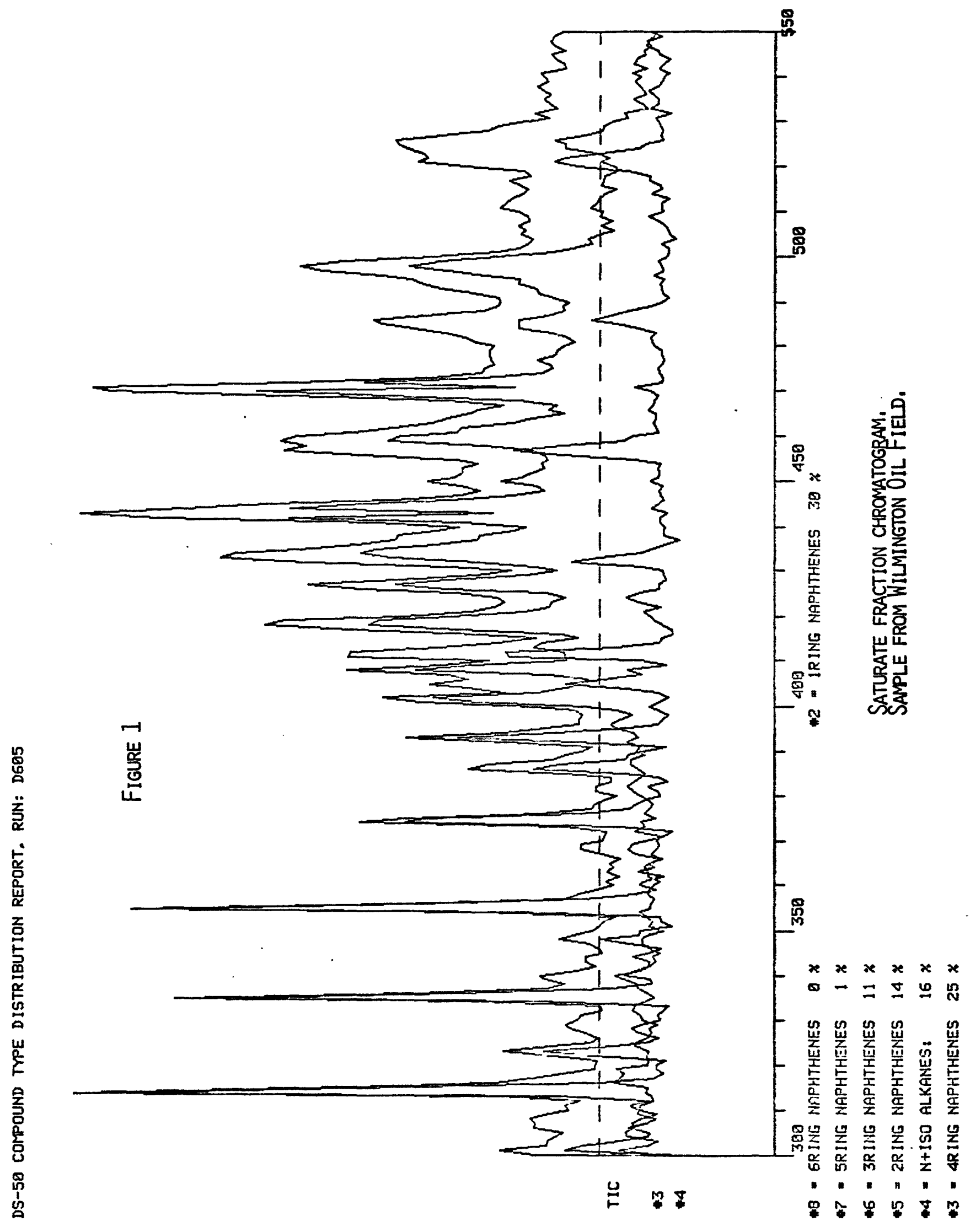



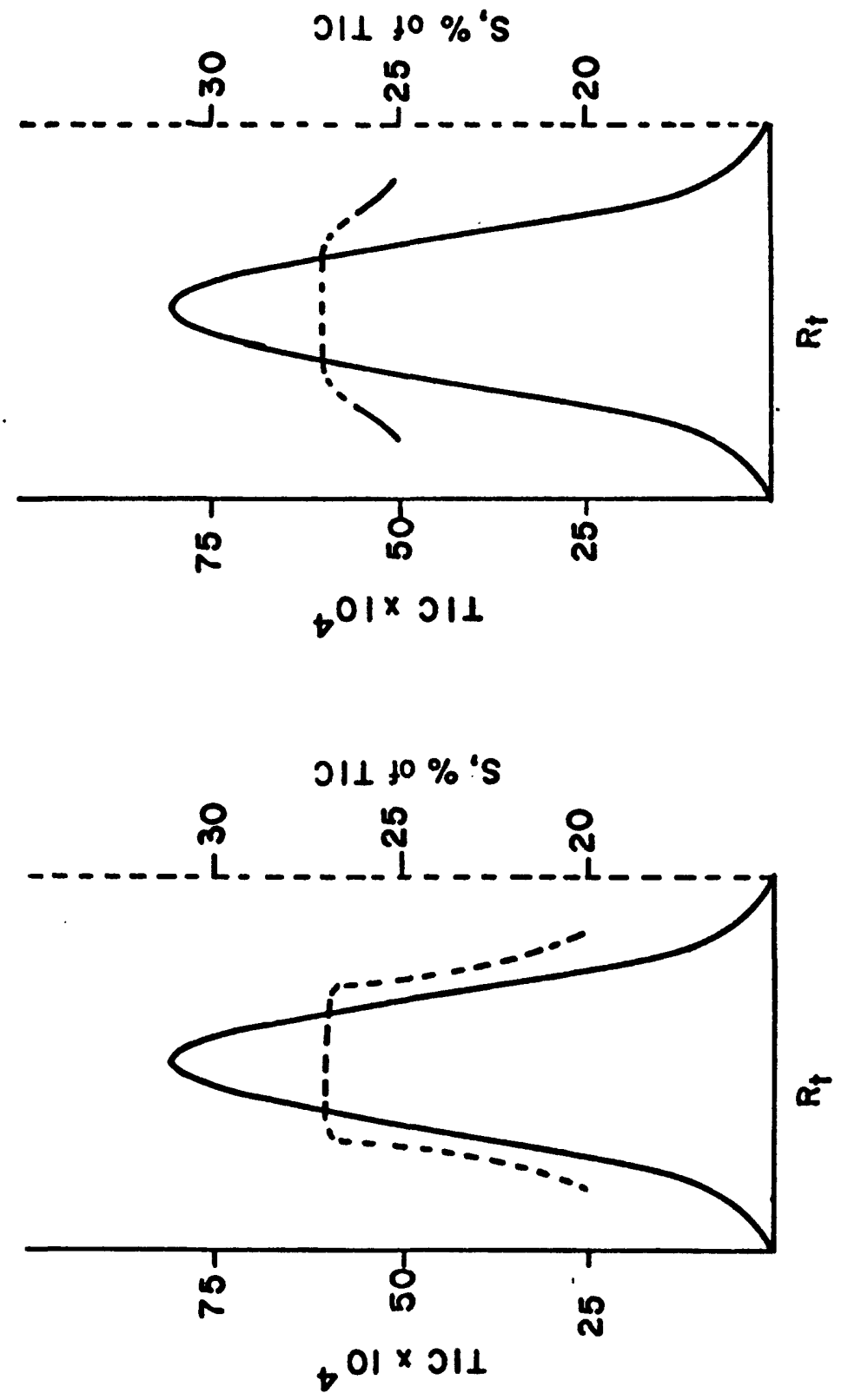


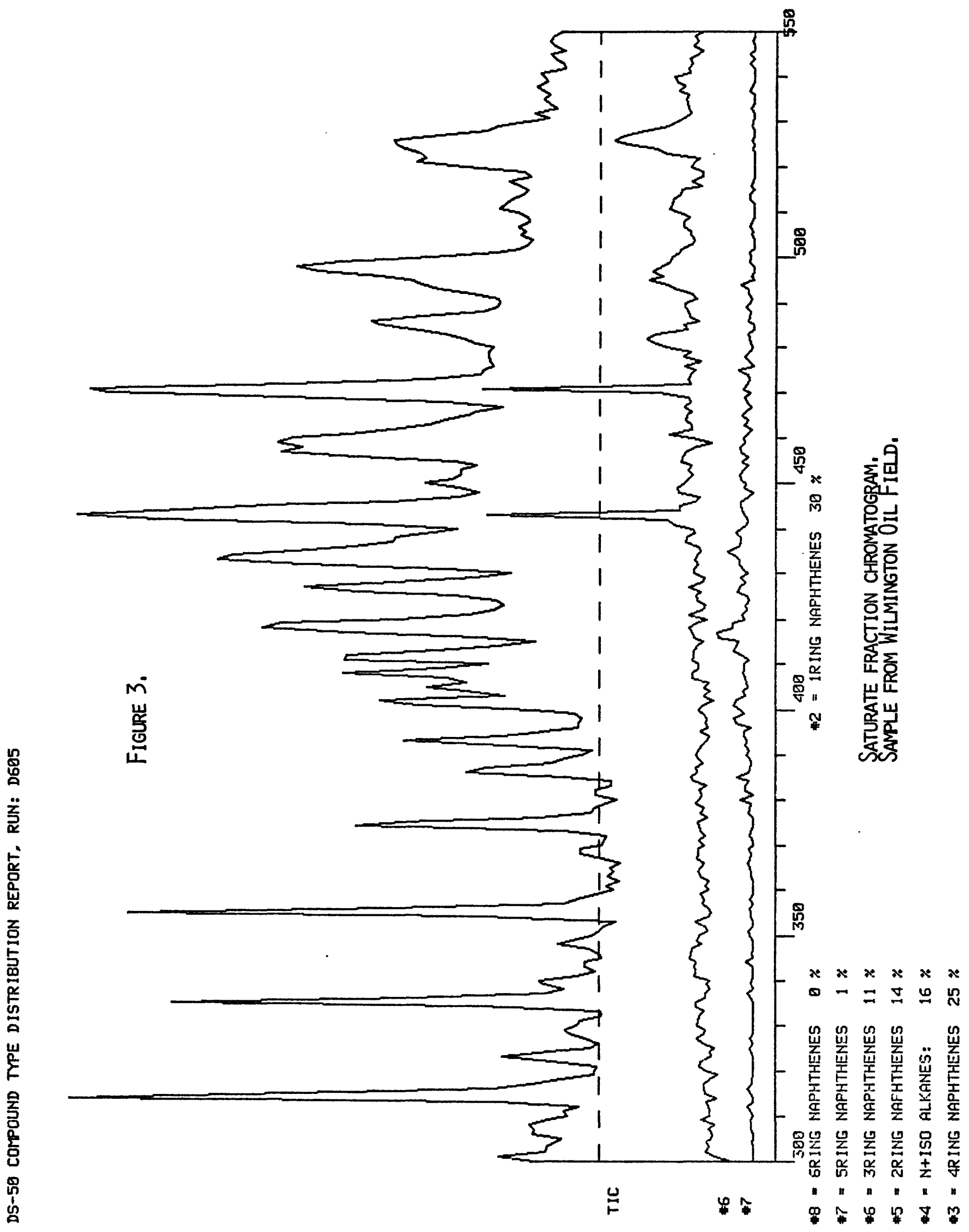

